\title{
AUCASSIN ET NICOLETTE O LA INVERSIÓN EN EL ROL DE GENEROS
}

\author{
Ramón García PRadas \\ Universidad de Castilla-La Mancha
}

\section{RESUMEN}

La chantefable que aquí nos ocupa, Aucassin et Nicolette, único ejemplo conservado del género, ha sido tradicionalmente definido, aunque con ciertas precisiones, como una parodia de buena parte de los géneros literarios medievales, y, especialmente, de la novela cortés. En buena medida, ello es así porque, con el devenir del relato, somos conscientes de que ciertos temas como el servicio de amor son burlados en la chantefable. Asimismo, el héroe no sabe comportarse como tal y la muchaca protagonista, símbolo máximo de alteridad en la obra, irá sufriendo progresivamente un proseso de masculinización con el que suple todas las carencias que el comportamiento de su amado presenta. No nos cabe la menor duda de que nos encontramos ante una mujer transgresora en el relato que nos ocupa. El héroe, hasta cierto punto, queda atrapado por toda una serie de valores tradicionalmente aceptados como femeninos, mientras que la protagonista principal, la joven Nicolette, logra erigirse como verdadera heroína, convirtiéndose así la chantefable en un verdadero himno a la mujer en la literatura Francesa del siglo XIII.

Dentro del amplio panorama literario relativo a la Francia medieval, el género de la chantefable es, como muy pertinentemente señala Liborio ${ }^{1}$, inusual y misterioso. Bossuat, por ejemplo, lo concibe como un género tremendamente ecléctico, donde, en cierto modo, se pueden reconocer buena parte de las manifestaciones más usuales de la $\mathrm{Li}$ teratura Francesa Medieval: «Tantôt vu comme un roman, un conte, une nouvelle, un fabliau, tantôt comme une composition dramatique. Aucassin et Nicolette "joue» finalement sur tous les tableaux, laissant à la fois une impression de style parlé et de pièce représentée ${ }^{2}$. No resulta, pues, tarea fácil la de clasificar esta pequeña obra conservada en

' M. LiBorio, «Aucassin et Nicolette: i limiti di una parodia», en Cultura Neolatina, 1970, 30, pág. 159.

${ }^{2}$ R. Bossuat et alii, Dictionnaire de lettres françaises. Le Moyen Âge, París, Le livre de Poche / La Pochothèque, 1964, pág. 112. 
un solo manuscrito copiado en la región de Picardía. Como hemos señalado, supone una mezcla de buena parte de los géneros literarios ya existentes, lo cual pone claramente de manifiesto el amplio bagaje literario que su autor debió presentar. Sin embargo, tal vez convendría precisar que la crítica no ha visto en esta fusión de géneros un mero producto azaroso, sino la intención paródica de su autor. De hecho, no han sido pocos los estudiosos que así lo han ratificado. Podríamos destacar a Harden ${ }^{3}$, Hunt $^{4}$, Jodogne $^{5}$, Martín ${ }^{6}$, Le Rider ${ }^{7}$, Roques $^{8}$ o Sargent ${ }^{9}$. Sin embargo, no todos aceptan de buen grado la etiqueta de parodia para definir la obra que aquí nos ocupa. Ménard ${ }^{10}$ así lo pone de manifiesto y Hunt" afirma que, cuando se habla de parodia, es preciso que el autor siga un determinado modelo mucho más de cerca de lo que nuestro autor hace. Por ello, cree conveniente precisar en torno al término parodia, abogando, antes bien, por el de pastiche $e^{12}$.

Bien cierto es que el autor de Aucassin et Nicolette parodia las formulas y motivos prototípicos del género épico, tales como el ritual que el caballero seguía cuando empezaba a armarse a fin de estar presto para el combate. De los romances más célebres toma también no pocos ejemplos. Así, de Pyrame et Tisbé alude al episodio en el que los jóvenes amantes, teniendo que verse a escondidas por las prohibiciones familiares que sobre ellos pesan, han de hablarse por la estrechez de la ranura de un muro. De la obra de Chrétien de Troyes y, más concretamente, de Yvain o Le chevalier au Lion y, sobre todo, de Lancelot o Le Chevalier à la Charrette, el autor de nuestra chantefable toma no pocos aspectos, a menudo con objeto de dotarlos de un cierto sabor burlesco que desencadenará la risa de un receptor (lector o auditor) bien familiarizado, en la época en la que nos encontramos, con la célebre obra de Chrétien de Troyes. Por ejemplo, en uno de los momentos en que Lancelot se encuentra atravesando una landa, queda tan absorto ante el pensamiento que en él despierta su amada que, incluso, se olvida de su propia existencia, de modo que cuando llega a un vado y su defensor lo desafía, Lancelot no se da cuenta de ello hasta que su enemigo lo ha dejado desarmado. Semejante actitud no la encontramos por parte de Aucassin cuando en medio de un combate no logra reaccionar ante los golpes que recibe de sus enemigos, de ensimismado que está al evocar con el pensamiento a su amada Nicolette. Asimismo, tampoco es ajeno el Tristan en la obra que aquí centra nuestra atención. De hecho, si recordamos, una de las formas en las que Tris-

\footnotetext{
${ }^{3}$ R. HARDEN, «Aucassin et Nicolette as parody», en Study in philology, 88, 1966, págs. 1-9.

${ }^{4}$ T. HUNT, «La Parodie Médiévale: le cas d’Aucassin et Nicolette», en Romania, 100, 1979, págs. 341-381.

${ }^{5}$ O. Jorogne, "La Parodie et le Pastiche dans Aucassin et Nicolette», en Cahiers de l'Association Internationale des Études Françaises, 12, 1960, págs. 53-65.

'J. H. Martin, Love's Fools: Aucassin, Troilus, Caliso and the Parody of the Courtly Lover, Londres, Tamesis, 1972.

${ }^{7}$ P. LE RIDER, «La parodie d'un thème épique: le combat sur le gué dans Aucassin et Nicolette», en Mélanges René Louis, 1982, págs. 1226-1235.

${ }^{8}$ M. Roques (ed.), Aucassin et Nicolette: chantefable du XIIle siècle, París, Honoré Champion, 1968.

${ }^{9}$ B. N. SARGENT, "Parody in Aucassin and Nicolette», en The French Review, 43, 1970, págs. 591-605.

17' P. MÉNARD, Le rire et le sourire dans le roman courtois en France au Moyen Âge (1150-1259), Ginebra, Droz, 1969, pág. 519.

$"$ T. Hunt, Op. cit., págs. 350-1.

${ }^{12}$ El pastiche, proveniente del italiano pasticcio, se define. en un principio, a nivel pictórico, como la imitación de un cuadro, realizada con tal habilidad que pudiera pasar por sus manos originales. A nivel literario, se refiere, evidentemente, a la imitación de obras literarias, especialmente cuando se imitan diversos textos y estilos en una misma obra (D. ESTÉBANEZ CALDERÓN. Breve diccionario de términos literarios, Madrid. Alianza Editorial, 2000, pág. 393).
} 
tán se acerca a Isolda, para poder disfrutar de unos breves instantes de amor, frente a la prohibición de verse que sobre ellos ha caído, es disfrazándose de juglar. En Aucassin et Nicolette encontramos este mismo episodio, si bien es la muchacha, Nicolette, quien transmuta su apariencia disfrazándose de juglar para poderse encontrar a escondidas, y sin ser reconocida, con el hombre al que más ama, es decir, el joven Aucassin.

Bastaría con tener en cuenta estos dos últimos ejemplos para constatar la eminente funcionalidad paródica o, cuando menos, burlesca que Aucassin et Nicolette ejerce con respecto a las obras y géneros que imita. De hecho, en la comparación con Lancelot, el descuido de Aucassin resulta harto hilarante, puesto que nuestro héroe ${ }^{13}$ ya se encuentra sumido en el conflicto bélico cuando su mente comienza a deleitarse en los placeres del amor. A su vez, en la comparación con Tristán, resulta gracioso ver cómo es la mujer, $\mathrm{Ni}$ colette en nuestro caso, y no el hombre, quien decide emprender la valiente hazaña de encontrarse con el amado, pese a saber que, si es descubierta, no tardarán en darle muerte.

En función de esta última idea, nos gustaría estudiar Aucassin et Nicolette desde la perspectiva de la inversión del rol de géneros, pues a lo largo de la obra, pese a su brevedad, hemos encontrado no pocos ejemplos donde el comportamiento de lo femenino tiende a masculinizarse, al tiempo que lo masculino se feminiza en no pocas ocasiones. Tal vez la parodia, si aceptamos el término a pesar de la controversia suscitada en algunos autores, como ya hemos observado, no sólo sea de índole literaria, a fin de conseguir un efecto cómico, sino también de conductas sociales y, más concretamente, de aquellas conductas que resultan esperables en un contexto esencialmente patriarcal y hegemónico como es el relativo a la Francia del medievo ${ }^{14}$. Comencemos, pues, a profundizar en la cuestión que nos ocupará a lo largo del presente artículo.

Nos gustaría empezar diciendo, sirviéndonos de las palabras de Badel, que «le chantefable tout entier joue du motif du monde renversé» ${ }^{15}$. No nos parece, en modo alguno, gratuito enfatizar esta idea, pues es precisamente lo que ocurre con las entidades de género que aparecen en nuestro relato, principalmente con Aucassin y Nicolette, protagonistas ambos que, de forma epónima, dan título a la obra. Ya en sus propios nombres se encuentra implícita una cierta idea de subversión. En efecto, mientras que Aucassin, príncipe provenzal y, por ende, cristiano, tiene un nombre de origen sarraceno ( $\mathrm{al} \mathrm{Ka}$ cem), según señala Payen ${ }^{16}$, la que verdaderamente es de origen sarraceno, pese a haber sido convertida al cristianismo, una vez que es comprada y conducida a Francia como esclava, es decir, Nicolette, «a un nom tout ce qu'il y a de plus français!»17.

Empecemos profundizando en el protagonista principal, símbolo de lo masculino en la obra que nos ocupa. De él ya hemos dicho que razones no faltan para que lo consideremos un anti-héroe. Su pasividad a lo largo de todo el relato o su abnegación a la hora de aceptar que no podrá realizar su amor junto a la mujer a la que por encima de to-

13 Ello hace que autores como Tattersall consideren a Aucassin un anti-héroe: «For while Nicolette is in all the usual senses of the word its heroine, Aucassin is not in the same straight-forward way the hero of the tale. Neither conventional nor consistent, is he, as some have claimed, an anti-héros and anti-chevalier (...)?» (J. TATTERSALL, «Shifting perspectives and the illusion of reality in Aucassin et Nicolette», en French Studies, 38, 1984, pág. 259.

${ }^{14} \mathrm{G}$. Duby, Mâle Moyen Âge. De l'amour et autres essais, París, Flammarion, 1988.

15 P. Y. BADEL, Introduction à la vie littéraire au Moyen Âge, París, Dunod, 1997, pág. 209.

16 J. C. PAYEN, Le Moyen Âge, París, Arthaud, 1990, pág. 249.

${ }^{17}$ P. Y. BADEL, Op. cit., pág. 209. 
do ama, la bella Nicolette, podrían ser criterios que así lo avalan. Es más, en él, y contrariamente a lo que sucede al héroe prototípico de la novela cortés, el hecho de amar lo aleja aún más de la proeza bélica. Aucassin no es capaz de aunar ambos conceptos en lo que para la cortesía supone el servicio de amor o proeza dedicada a la dama para ganar el favor de su corazón. El joven, por el contrario, se niega, incluso, a luchar contra los enemigos de su padre. La única actividad es la de lamentarse de sus desdichas sentimentales mientras permanece encerrado en sus aposentos. De hecho, bien podríamos decir que esta constante fusión que existe entre el espacio cerrado y el personaje masculino resulta, cuando menos, sorprendente, puesto que la Literatura Medieval se ha caracterizado, antes bien, por ligar al héroe masculino a los espacios abiertos, dejando para la mujer el confinamiento que ha de esperarse en el espacio cerrado. Del mismo modo, podríamos añadir que Aucassin no es un hombre que se da a la acción, como cabría esperar, sino a la reflexión, lo cual ratifica una vez más la proyección interiorista de este personaje, algo que, en principio, sería más esperable en el ámbito de lo femenino. Sobre este interiorismo y esta carencia de brío y vigor que se acusan sorprendentemente en el carácter de Aucassin, Stanesco nos dice: «Il est indifférent à tout ce qui ne concerne pas son amour, y compris au salut de son âme» ${ }^{18}$. Es más, como indican Payen y Garel, «l'amour conduit le héros à se montrer lâche» ${ }^{19}$. Así, el amor, lejos de ennoblecer y forjar al héroe, parece estar envileciéndolo y acobardándolo.

Desde luego, bien cierto es que a lo largo de la Literatura Francesa del medievo nos encontramos con no pocos ejemplos de héroes que por amor se han desvinculado de su deber épico, pero tal desvinculación no llega a ser más que ocasional o fortuita. Podríamos pensar, por ejemplo, en Tristán. Una vez que el joven héroe se une carnal y sentimentalmente a Iseo, el ritmo de proezas bélicas disminuye considerablemente, pero el afán de aventura y lucha no desaparece en el joven. Así, cuando se encuentra en el exilio, lucha valerosamente para defender al rey Arturo o al padre de Iseo de las Blancas Manos. Si la presencia de la mujer y el dominio de lo erótico habían anulado la capacidad épica del héroe, la ausencia de la mujer en escena y, sobre todo, en su vida, hace que éste pronto recupere su deber en tanto que caballero. Ejemplos similares los podemos encontrar en las novelas de Chrétien de Troyes. Por ejemplo, Yvain, cuando contrae matrimonio con Laudine, permanece a su lado por un buen periodo de tiempo sin emprender aventura alguna hasta que Arturo y su hueste lo visitan y lo incitan a que vuelva a tomar las armas. En el caso de Erec, nos encontramos ante una problemática hasta cierto punto similar, ya que el héroe, cuando contrae matrimonio, se abandona a los dulces placeres del hogar en compañía de su esposa Enide hasta que se entera de que sus compañeros han empezado a criticarlo y a tacharlo de cobarde. La capacidad de reacción, algo de lo que carece Aucassin, será inmediata en Erec, dejando su hogar y marchando en compañía de su esposa en busca de proezas que le lleven a recuperar la gloria heroica de antaño. Aucassin, sin embargo, siempre se niega a participar en cualquier proeza de índole bélica, aún, incluso, cuando el reino de su padre corre grave peligro:

Mais si estoit soupris d'Amor, qui tout vaint, qu'il ne voloit estre cevalers, ne les armes prendre, n'aler au tornoi, ne fare point de quanque il deust (...) Ses pere et se mere li disoient:

${ }^{18}$ M. Stanesco, Lire le Moyen Âge, París, Dunod, 1998, pág. 95.

19 J. Garel y J. C. PAYen, «Le roman médiéval au XIle et au XIIIe siècle", en P. Abraham (ed.), Histoire littéraire de la France. Des origines a I600, París, Messidor» / Éditions Sociales, 1971, pág. 229. 
«Fix, car pren tes armes, si monte el ceval, si deffent te terre et aïe tes homes: s'il te voient entr'ex, si defenderont il mix lor cors et lor avoirs et te tere et la miue» ${ }^{20}$.

Aucassin sólo accederá a tomar las armas y luchar por el reino de su padre a condición de que éste le permita, al menos, intercambiar un beso y unas cuantas palabras con su amada Nicolette. El padre así lo hace y, entonces, Aucassin toma las armas y se enfrenta en combate a sus enemigos, pero en lugar de luchar valerosamente, el joven queda ensimismado pensando en su dama. El amor, por lo tanto, lejos de ser una excusa para el cumplimiento de la proeza, es el fin de la misma. La proeza, por consiguiente, sólo es secundaria y, por ello, Aucassin, tras recibir una buena tunda de golpes, está apunto de ser hecho prisionero, tal y como apunta Pauphilet: «Ces pensées, au rebours de la doctrine courtoise, ne lui inspirent aucune prouesse, mais au contraire l'absorbent en elles mêmes, au point qu'il ne s'aperçoit pas qu'on le fait prisonnier ${ }^{21}$. Únicamente cuando ya teme por su vida, pues, de morir, ello le impediría encontrarse con Nicolette, Aucassin reacciona y lucha valerosamente, como un verdadero y aguerrido soldado. Solo entonces Aucassin logra acompasar su identidad de género con lo que la sociedad espera de él, proclamándose así héroe vencedor en el reino del padre:

Li vallés fu grans et fors, et li cevax so quoi il sist fu remuans. Et il mist le main a l'espee, si comence a ferir a destre et a senestre et caupe hiaumes et naseus et puins et bras et fait un caple entor lui, autresi con li senglers quant li cien l'asalent en le forest, et qu'il lor abat dis cevaliers et navre set et qu'il se jete tot estroseement de la prese et qu'il s'en revient les galopiax ariere, s'espee en sa main ${ }^{22}$.

Sin embargo, el premio o sanción a la proeza de Aucassin no se cumple y el joven vuelve a quedar sometido a la autoridad patriarcal. Lejos de revelarse contra ella para defender el amor que siente, Aucassin se encierra para lamentarse de su situación. El amor lo hace así prisionero, dejando anuladas sus cualidades masculinas. La pasividad de Aucassin no le permite, pues, desarrollarse ni como guerrero ni como hombre, siendo sólo víctima y presa de su propio deseo:

Douce amie, flors de lis,

Biax alers et biax venirs,

Biax jouers et biax bordirs,

Biax parlers et biax delis,

Dox baisiers et dox sentirs,

Nus ne vous poroit haï.

Por vos sui en prison mis

En ce celier sousterin

$\mathrm{U}$ je fac mout male fin;

Or m'i convenra morir

Por vos, amie ${ }^{23}$.

${ }^{20} \mathrm{~J}$. Dufournet, Op. cit., pág. 44.

${ }^{21}$ A. PAupHILet, Le legs du Moyen Âge: études de littérature médiévale, Melun, Librerie d'Aregences, 1950, pág. 242.

${ }^{22} \mathrm{~J}$. Dufournet, $O p$. cit., pág. 70.

${ }^{23}$ J. Dufournet, Op. cit., pág. 76. 
Como se puede fácilmente constatar, Aucassin presenta una naturaleza poco uniforme. Ha sido capaz de demostrarnos que puede llegar a ser un héroe, pero no osa enfrentarse a los problemas familiares que le impiden desarrollarse plenamente y es esta pasividad la que, inconscientemente, le hace abogar por un comportamiento que tiende hacia la feminización desde el momento en que es él quien espera en la búsqueda amorosa y será la mujer quien realmente se convierta en sujeto operador o en la verdadera heroína activa que cumpla con esta búsqueda.

Anteriormente hemos dicho que el proceso de feminización es inconsciente en Aucassin. Con la victoria frente a los enemigos de su padre, el joven nos ha demostrado que puede llegar a ser un héroe. Asimismo, existe otra prueba en el devenir del relato que nos ratifica una vez más el rechazo que en el fondo Aucassin siente por la inversión del rol de género de la que él, en realidad, está siendo víctima. Nos referimos a la escena en la que, una vez que los jóvenes enamorados se fugan, llegan por azar al reino de Torlore y cuando Aucassin descubre que el rey finge haber dado a luz y lo pone como excusa para no ir a la guerra, permitiendo así que sea su mujer la que se encuentre a la cabeza del ejercito, la repulsión de Aucassin es tal ante tamaña inversión de género (el rey, es decir, el símbolo máximo de lo patriarcal y hegemónico se feminiza hasta el punto de hacer el papel de madre recién dada a luz) que su reacción inmediata no puede ser otra que la de dar una tunda de palos al rey, quien, en el fondo, sólo es un reflejo exagerado y esperpéntico de lo que a él mismo le ocurre, así como la de prohibir que cualquier otro hombre de ese reino no se acueste fingiendo los dolores de parto tras haber tenido un hijo:

\author{
(...) \\ Di va! fau, que fais tu ci? \\ Dist li rois: <<Je gis d'un fil. \\ Quant mes mois sera complis \\ Et je serai bien garis, \\ Dont irai le mece oïr, \\ Si com mes ancestre fist, \\ Et me grant guerre esbaudir \\ Encontre mes anemis: \\ Nel lairai mie» \\ $\mathrm{XXX}$ \\ OR DIENT ET CONTENT ET FABLOIENT
}

Quant Aucassins oï ensi le roi parler, il prist tox les dras qui sor lui estoient, si les houla aval le canbre. Il vit deriere lui un baston, il le prist, si torne, si fiert, si le bati tant que mort le dut avoir.

«Ha! Biax sire, fait li rois, que me demandés vos? Avés vos le sens dervé, qui en me maison me batés?

- Par le cuer Diu! Fait Aucassins, malvais fix a putain, je vos ocirai, se vos ne m'afiés que ja mais hom en vo tere d'enfant ne gerra ${ }^{24}$.

${ }^{24}$ J. DUFOURnet, Op. cit., págs. 132-134. 
Desde luego, todo es absurdo en Torlore, como lo demuestra el hecho de que nos encontremos a la mujer del rey, recién dada a luz, a la cabeza de una guerra donde las armas arrojadizas no son otra cosa que patatas blandas, huevos y queso fresco. Desde luego, hemos de admitir, como muy bien hace Stanesco, que «Torlore n'est pas l'embryon d'une quelque utopie, mais l'image d'un monde renversé ${ }^{25}$. No se trata, en efecto, de una utopía, sino del reflejo de un mundo al revés en el que hombres y mujeres parecen tener papeles invertidos: los unos sumidos en su sufrimiento y las otras al frente de la guerra, como luchadoras heroicas. Torlore es, pues, en el grado más elevado de comicidad, el reflejo de la realidad que subyace a Aucassin y Nicolette, puesto que continuamente vemos a Aucassin llorar y sufrir por amor: «(...) si recomence a plorer / tout por s'amie» ${ }^{26}$, mientras que Nicolette, mujer que lucha activamente por defender su amor, siendo capaz de afrontar cualquier proeza, aunque ello le pueda costar, incluso, la vida, podría ser considerada la verdadera heroína del relato que aquí nos ocupa. Roger nos dice a este respecto:

C'est toujours Nicolette qui prend l'initiative, suivie, comme de son ombre, par Aucassin. Nicolette est la femme qui appelle, dirige et domine le mâle : son écho. (...) Il n'y a que Nicolette qui soit réellement active : elle cherche les moyens de salut, affronte les dangers les plus terribles. À peine mise dans sa haute prison, elle est décidée à ne pas rester ... tandis qu'Aucassin, dans la même situation, ne fait que désespérer. Aucassin n'est pas actif : ses faits et gestes ne sont que l'imitation de ce qui arrive à Nicolette ${ }^{27}$.

Frank comparte esta misma idea cuando compara y destaca por su singularidad a Nicolette frente al grueso de heroínas que desfilan por la producción novelística medieval: «where the heroines of the romances usually remain placidly on their pedestals to be worshipped, the enterprising Nicolette initiates such slight action as the story progresses» ${ }^{28}$, lo cual le permite concluir que Nicolette, en comparación con Aucassin, es la más resuelta de los dos. Parece, pues, que la comparación entre los jóvenes enamorados resulta inevitable, puesto que aquello que le falta a Aucassin, Nicolette lo presenta como característica esencial de su personalidad. La complementariedad es, pues, perfecta. Si Aucassin es víctima de su pasividad, Nicolette, por el contrario, siempre se nos muestra como un personaje activo y con iniciativa propia: «Thus, a Nicolette who was generically to be the passive female love object is revealed - reveals herself, really - to be the active authoritative figure, and thus a marked contrast with Aucassin ${ }^{29}$. Nicolette, en el fondo, podría definirse ante los ojos del lector como una mujer llena de vida, una mujer que, sorprendentemente, ha robado el protagonismo heroico al personaje masculino. Es, pues, una heroína muy poco convencional en el periodo literario que nos ocupa, una heroína que quizá sobresale con más fuerza y vigor debido a la continua comparación que

\footnotetext{
${ }^{25}$ M. Stanesco, Op. cit., p. 96.

${ }^{26} \mathrm{~J}$. DUFOURNET, Op. cit., p. 82.

${ }^{27} \mathrm{~K}$. ROGGER, «Etude descriptive de la chantefable Aucassin et Nicolette», en Zeitschrift für romanische Philologie, 70, 1954, p. 50.

${ }^{28}$ G. Frank, The Medieval French Drama, Oxford, Clarendom Press, 1954, p. 238.

${ }^{29}$ R. M. MEnolcal, "Signs of the times, self, other and history in Aucassin et Nicolette», en The Romanic Review, 80, 1989, pp. 497-511.
} 
de ella se hace en el relato con respecto a su amado Aucassin: «That the author means us to compare Aucassin with Nicolette is suggested by the many parallels he sets up between them (...) One finds, on the contrary, that Aucassin can only suffer by the comparison; this seems the predominant critical view $»^{30}$. En efecto, la continua comparación a la que ambos personajes están sometidos no es, en modo alguno, gratuita o azarosa. Antes bien, se trata de un efecto estratégicamente buscado por parte del autor en el lector / auditor, exponiéndolo así a no pocas escenas o descripciones comunes en las que los dos protagonistas siempre aparecen por separado. Podríamos hacer mención, en este sentido, a la escena en la que ambos se encuentran prisioneros o al encuentro que cada uno tiene por separado con los pastores que luego les ayudarán a que se encuentren. El resultado de esta comparación no es otro que la ridiculización de Aucassin y el ensalzamiento de Nicolette, tal y como señala Crossland, cuando, sobre la protagonista femenina, nos dice que es «much more energetic than her slightly spineless lover ${ }^{31}$, lo cual hace que, en definitiva, el éxito final o la sanción positiva que sirve de colofón a nuestro breve relato se deba, en el fondo, «au courage et à l'habilité de Nicolette» ${ }^{32}$, es decir, a la iniciativa de «une héroïne très dégourdie» ${ }^{33}$. Nicolette, heroína que ha robado un puesto que la literatura concedía sin cuestionamiento alguno al género masculino, merece, pues, un tratamiento más profundo en este artículo en el que la obra objeto de estudio podría considerarse perfectamente como un himno a la mujer ${ }^{34}$.

Resulta ya sorprendente que el autor de la chantefable nos describa a Nicolette como una mujer cuyos rasgos físicos se corresponden a la perfección con la belleza cortés que se tiene en Francia durante el medievo:
Nicole est en prison mise
En une canbre vautie,
Ki faite est par grant devisse,
Panturee a miramie.
A la fenestre marbrine
La s'apoia la mescine.
Ele avoit blonde la crigne
Et bien faite la sorcille,
La face dore et traitice:
Ainc plus bele ne veïstes ${ }^{35}$

Incluso, su nombre, como ya hemos apuntado en algún momento, presenta un claro origen francés. También sabemos que es cristiana conversa, aspecto que nos pone claramente de manifiesto que la protagonista femenina de nuestro relato va a estar estrechamente ligada al ámbito de la alteridad. En efecto, su origen es sarraceno y ha sido com115

${ }^{30}$ R. S. SPRAYCARD, «Genre and convention in Aucassin et Nicolette», en Filoloxia, 76, 1985, pp. 94-

${ }^{31}$ J. Crossl.AND, Medieval French Literature, Oxford, Basil Blackwell, 1956, p. 86.

${ }^{32}$ M. Roques, Op. cit., p. 7.

${ }^{33}$ E. Baumgartner, La littérature française du Moyen Âge, París, Dunod, 1999, p. 64.

34 J. DUFOURNET, Op. cit., p. 24.

35 J. DUfOURnEt, Op. cit., p. 54. 
prada como esclava por un rico terrateniente francés. Aunque conversa, ante los ojos de los cristianos franceses es vista como alguien diferente. De ahí que sea imposible aceptarla dentro de la comunidad. Socialmente, no deja de ser una mujer que ha sido comprada en calidad de esclava, aunque su señor la haya convertido en filleule. Todo ello no puede provocar otra cosa que repulsión, aspecto que se constata en la primera parte del relato con el rechazo y la enemistad manifiesta que el padre de Aucassin siente por la joven desde el momento en que se entera de que su hijo pretende tener relaciones con la muchacha:

«Sire quens, car ostés Nicolette vostre filole! Que la tere soit maleoite dont ele fut amenee en cest païs! C'or par li pert jou Aucassin, qu'il ne veut estre cevaliers, ne faire point de quanque faire doie. Et saciés bien que, se je le puis avoir, que je l'arderai en un fu, et vous meismes porés avoir de vos tote peur» ${ }^{36}$

Tanta alteridad y, sobre todo, tamaño rechazo no pueden provocar otra cosa que el confinamiento de Nicolette, quien termina cautiva en el palacio de su señor a condición, al menos, de poder conservar la vida.

A partir de este momento se empezará a producir la trasgresión llevada a cabo por la muchacha, pues lejos de resignarse, como ocurre en el caso de Aucassin, Nicolette luchará valerosamente por defender su amor contra las opresiones que la autoridad patriarcal y hegemónica le ha impuesto (nos referimos al encierro al que la ha sometido su señor el vizconde o a la amenaza de muerte de Garin de Beaucaire, padre de Aucassin, si la muchacha llega a ver a su hijo o se acerca a él). Sin embargo, Nicolette decide una noche escaparse por la ventana del castillo, aprovechando que su vieja guardiana dormía $y$, no contenta con ello, se dirige a la torre donde permanece encerrado su enamorado, llegando, incluso, a hablar con él. El grado de valentía de Nicolette no es, en absoluto, desdeñable, especialmente si lo ponemos en parangón con la actitud de Aucassin, quien, cuando descubre que su amada ha ido a verle, rompe a llorar, sin que se le pase por la cabeza tomar la decisión de fugarse con su amada o de luchar para defenderla del agravio que se está cometiendo contra su persona. El rol activo de Nicolette pone, pues, de manifiesto que la inversión de roles en la identidad de género es recíproca en los protagonistas del relato, pudiéndose así asimilar a Nicolette con el ámbito de la actividad y de la heroicidad: «Thus, a Nicolette who was generally to be the passive female love object is revealed - reveals herself really - to be the active authoritative figure, and thus a marked contrast with Aucassin » ${ }^{37}$. En definitiva, bien podríamos decir que la inversión del rol de género en Nicolette la va a acercar a lo largo de todo el relato a actividades prototípicamente masculinas. No en vano, Mckean, a la hora de comparar a la protagonista femenina con Aucassin, nos dice: «Nicolette's decisive activity is downright virile» ${ }^{38}$. Esta virilidad y esta valentía en Nicolette queda puesta de manifiesto en el relato cuando, al marcharse del lugar en el que se encuentra su amado, atraviesa el campo agreste de noche hasta que llega a la fosa del castillo y se tira por ella, pese a que le pueda causar la muerte, a fin de liberarse de la ignominia pública de la que podría llegar a ser víctima en caso de ser descubierta:

\footnotetext{
36 J. DUFOURnet, Op. cit, p. 50.

${ }^{37}$ R. M. MENOCal, Op. cit., p. 505.

${ }^{38}$ M. F. MCKEAN, «Torlore and Courtoisie», en Romance Notes, 3, 1961-2, pp. 66.
} 
«Hé! Dix, fait ele, douce Creature! Se je me lais caïr, je brisarai le col, et se je remain ci, on me prendera demain si m'arde on en un fu. Encor ainme je mix que je muire ci que tos li pules me regardast demain a merveilles». Ele segna son cief, si se laissa glacier aval le fossé, et quant ele vint $u$ fons, si bel pié et ses beles mains, qui n'avoient mie apris c'on les bleçast, furent quaissies et escorcies et li sans en sali bien en dose lius, et ne por quant ele ne santi ne mal ne dolor por le grant paor qu'ele avoit ${ }^{39}$.

En cualquier caso, con esta primera visita de Nicolette para reunirse con su amado, de alguien que es prisionero de su amor en un sentido figurado, pero no real, como ha sido el caso de Nicolette al quedar confinada y custodiada por un ama siguiendo las órdenes del vizconde, constatamos cómo es la mujer quien realiza la proeza de encontrarse con el amado y no al contrario, como cabría esperar y como, de hecho, suele suceder en la novela cortés. En este orden de ideas, Aucassin et Nicolette bien podría ser una transposición de lo que ocurre en Lancelot o en Tristán e Isolda. En el primer ejemplo, es Lancelot quien parte en busca de Ginebra al reino del rey Badegamu para librarla del malvado Maléagant. En cuanto a Tristán, no son pocas las ocasiones en las que el joven se disfraza de mendigo, de leproso, de loco y de juglar ${ }^{40}$ para ir a ver a su amada. Bien podríamos considerar, desde luego, la actitud de Nicolette como una parodia más que evidente del héroe cortés.

Nicolette continúa así su viaje iniciático, afianzándose cada vez más su carácter heroico y viril, como podemos constatar, por ejemplo, cuando decide adentrarse sola en los peligros del bosque, aunque allí tenga que enfrentarse, incluso, con fieras salvajes:

«Peres, rois de maïesté,

or ne sai quel part aler:

se je vois u gaut ramé,

ja me mengeront li lé,

li lion et li sengler

dont il i a a plenté;

et se j'atent le jor cler

que on me puist ce trover,

li fus sera alumés

dont mes cors iert enbrasés.

Mais, par Diu de maïsté,

Encor aim jou mix assés

Que me mengucent li lé,

$\mathrm{Li}$ lion et li sengler,

Que je voisse en la cité:

Je n'irai i mie»"

${ }^{39} \mathrm{~J}$. DufouRnEt, Op. cit., p. 90.

${ }^{40}$ En Aucassin et Nicolette encontramos también el episodio en el que uno de los amantes se disfraza de juglar para ver al otro, pero en este caso es la mujer quien osa hacerlo, transponiendo así, en lo que se refiere a la identidad de género, lo que ocurre en Tristan et Yseut. De todos modos, sobre este aspecto, tan relevante para la cuestión que nos ocupa, hablaremos más adelante.

${ }^{41}$ J. DufOuRnET, Op. cit., p. 94. 
Nicolette sigue adentrándose en el bosque de noche, es decir, en el momento en el que prima lo dionisiaco, tan relacionado en literatura con el ámbito de lo femenino. Podríamos decir, por ello, que indirectamente existe un cierto afán por parte del autor de nuestra chantefable de adaptar la aventura de Nicolette al contexto de feminidad que, en calidad de mujer, le corresponde. Como es lógico, lo dionisiaco conduce a lo onírico y así, Nicolette, agotada por lo arduo del camino, se duerme. Cuando despierta, se encuentra a unos pastores que, sorprendidos ante la contemplación de tanta belleza, la toman por un hada: «Vos estre fee, si n'avons cure de vo conpaignie, mais tenés vostre voie ${ }^{42}$. La alteridad provoca una vez más rechazo en aquellos que contemplan y se relacionan con Nicolette, pero la joven consigue hacer prevalecer su punto de vista, convenciendo, a cambio de una suma de dinero, a los pastores para que, cuando vean a Aucassin, le digan que vaya al bosque a cazar una bestia maravillosa, pues sólo ella podrá curarlo de la herida de amor que el joven padece ${ }^{43}$. Realmente, no existe tal bestia, como los mismos pastores dejan ver: «C'est fantosmes que vos dites, qu'il n'a si ciere beste en ceste forest, ne cerf, ne lion, ne sengler, dont uns des membres vaille plus de dex deniers u de trois au plus, et vos parlés de si grant avoir!» ${ }^{44}$. Es evidente que Nicolette está hablando en términos metafóricos, pues, en efecto, es ella quien puede curar a $\mathrm{Au}$ cassin de su mal de amor si logra encontrarla en el bosque. Cuando Aucassin se encuentra con los pastores, éstos le dicen lo que Nicolette les había encomendado y atisbamos así, sorprendentemente, un gesto de heroicidad por parte del personaje masculino en un momento en que Nicolette parece haberse convertido en objeto de deseo y búsqueda, rol prototípico de la mujer desde que logra librarse del yugo de pasividad al que la canción de gesta la tenía sometida ${ }^{45}$.

\author{
Or parla, s'a dit trois mos: \\ «Nicolette o le gent cors, \\ por vos sui venus en bos: \\ je ne cac ne cerf ne porc, \\ mais por vos siu les esclos. \\ Vo vair oeil et vos gens cors, \\ Vos biax ris et vos dox mos \\ Ont mon cuer navré a mort. \\ Se Dix plaist le pere fort, \\ Je vous revería encor, \\ Suer, douce amie» ${ }^{46}$.
}

42 J. Dufournet, Op. cit., p. 98.

${ }^{43}$ El motivo del amante herido y condenado a ser curado por una mujer, puesto que realmente está enfermo de amor, no es original en la chantefable que nos ocupa. Por ejemplo, ya lo podemos encontrar en los Lais de Marie de France y, más concretamente, en el lai que lleva por título Guigemar.

${ }^{44} \mathrm{~J}$. DUFOURNET, Op. cit., p. 98.

${ }^{45}$ A este respecto, Dessaint nos dice: «Elles n'ont plus un rôle accessoire comme dans les chansons de geste : elles deviennent le but proclamé de la quête et les portraits qui sont faits d'elles dans leur diversité et leur humanité, rendent plausible le fait que les hommes abandonnent tout pour elles» (M. DESSAINT, La femme médiatrice dans de grands auvres romanesques du XIIe siècle, París, Honoré Champion, 2001, p. 51).

${ }^{46} \mathrm{~J}$. Dufournet, Op. cit., p. 112. 
Sin embargo, no hemos de ver en esta actitud una transposición de los valores de la identidad de género de acuerdo a lo que sería esperable. En efecto, ha sido Nicolette quien ha propiciado el encuentro y quien ha llegado a construirse, incluso, una cabaña en el bosque para esperar así la llegada de su amado ${ }^{47}$.

Acto seguido, los amantes huyen al reino de Torlore, donde, como ya comentábamos, el mundo parece estar invertido, puesto que la reina ocupa el lugar que correspondería al rey, luchando en la guerra al frente de su ejercito, y el rey el lugar que correspondería a la reina, guardando cama después de haber dado a luz. En definitiva, el mundo de Torlore no es otra cosa que un reflejo hilarante llevado al absurdo de lo que verdaderamente ocurre con Aucassin y Nicolette.

Finalizada su estancia en Torlore, el relato nos precipita a un nuevo episodio en el que el poder y la identidad de Nicolette son reforzados a nivel social. En efecto, tras haber sido separados los amantes por una terrible tormenta, Nicolette llega azarosamente al reino de su padre y allí descubre su verdadero origen, pues resulta ser la hija del rey. Desde luego, hemos de aceptar que el episodio es artificial en extremo. Si admitimos, como nos dice el relato, que cuando raptan a Nicolette, la joven ya era lo suficientemente mayor como para recordar ${ }^{48}$ su origen, no podemos comprender cómo ha podido olvidarlo estando en Francia. Nos gustaría citar las palabras esclarecedoras de Jodogne al respecto:

Que Nicolette ait oublié le nom d'un pays qu'elle avait quitté très tôt, admettons-le ; mais qu'elle ne soit plus souvenue d'être la fille d'un roi, puis que les murs de Carthage lui ait rappelé soudain sa destinée, bien plus, que le roi de Carthage l'ait crue sur parole, c'est invraisemblable ${ }^{49}$.

A pesar de no estar de acuerdo con las palabras de Jodogne, hemos de reconocer, sin embargo, que la artificiosidad en el viaje de regreso de Nicolette a su patria de origen y la inverosimilitud de su pérdida de memoria son elementos absolutamente necesarios en el devenir del relato porque permiten equiparar socialmente a Nicolette con Aucassin (si Nicolette era antes una esclava, ahora pasa a convertirse en una princesa) y, también, porque el que Nicolette termine descubriendo su verdadera identidad es un rasgo más que acerca el personaje femenino al prototipo de héroe que encontramos en la novela medie$\mathrm{val}^{50}$, es decir, que el relato incide una vez más en la inversión de la identidad de géneros que había empezado ya tomando cuerpo desde que Aucassin se encierra en sus aposentos para lamentar la pérdida de Nicolette y desde que ésta huye de su confinamiento para recuperar la libertad prohibida e, indirectamente, poder volver junto a Aucassin.

En cualquier caso, Nicolette, pese a haber recuperado su verdadera identidad al saberse hija del rey de Cartago, se siente como una verdadera extraña en su país. Así, si

${ }^{47}$ La construcción de la cabaña en el bosque también es uno de los motivos que aparecen reflejados en Tristan et Yseut, concretamente, cuando los amantes se exilian en el bosque del Morrois, pero, a diferencia de lo que ocurre en Aucassin et Nicolette, la cabaña había sido construida por el hombre, como es de esperar.

${ }^{48}$ En efecto, el texto nos dice: «(..) quant Nicolette vit les murs del castel et le païs, ele se reconut, qu'ele $i$ avoit norie et pree petis enfes, mais ele ne fu mie si petis enfes que ne seust bien qu'ele avoit esté fille au roi Cartage et qu'ele avoit esté norie en la cité» (J. DUFOURNET, Op. cit., p. 146).

${ }^{49}$ O. Jodogne, Op. cit., p. 63.

${ }^{50}$ R. S. SPRAYCAR, op. cit. p. 100. 
Nicolette, por sus orígenes, era vista como la alteridad árabe en el contexto cristiano, ella se ve como la alteridad cristiana en el contexto árabe. No perdamos de vista que hace ya no poco tiempo que ha sido convertida al cristianismo y que sus rasgos e, incluso, su nombre son de origen cristiano y francés. Por ello, a pesar de que le proponen cuantiosos matrimonios con príncipes, la joven siempre los rechaza, pues en su fuero interno sólo hay espacio para el amor que siente por Aucassin. Hemos de advertir que, si bien Aucassin también podría ser visto por Nicolette como signo de alteridad, en su conciencia no hay rechazo alguno, sino el deseo de integrar aquello que es diferente. No en vano, Menocal apunta a este respecto: «She has no illusions about Difference but sees it, as much of the twelfth century in Europe clearly did as well, as the best reason for union and appropriation» ${ }^{51}$. A las palabras de Menocal podríamos añadir que este deseo de unión de la diferencia también se encuentra presente en Aucassin, si bien no resulta ser tan palpable como en el personaje femenino, debido a la tremenda pasividad con la que se concibe al personaje de Aucassin desde el comienzo del relato.

Para poder realizar, entonces, su deseo, Nicolette decide regresar a Beaucaire al encuentro de Aucassin. Sin embargo, no lo hace como Nicolette y el proceso de masculinización en la identidad de la heroína llega a su punto álgido al embadurnar su cara con tinte negro y vestirse de juglar, es decir, de hombre, en definitiva. Así, si por amor se había marchado de Beaucaire una joven francesa y cristiana, por amor regresa un trovador sarraceno de piel oscura. Nicolette hace, pues, gala de su alteridad en todos los sentidos: en el ámbito de la identidad de género y también en el ámbito racial. Cuando ve al desesperado Aucassin, el joven no la reconoce, pero Nicolette escucha de su parte lo que quiere escuchar, la confesión de amor que ha lugar cuando manda al trovador a que vaya en busca de Nicolette para decirle lo mucho que la quiere y pedirle que vaya a reunirse con él. El trovador se marcha y, en privado, vuelve a recuperar su verdadera identidad femenina. Entonces, manda llamar a Aucassin, el joven reconoce a Nicolette y, como en el cuento tradicional, todo termina en feliz matrimonio, produciéndose así la sanción positiva en el programa de la búsqueda y la realización del amor verdadero:

Quant ele voit son ami,

Or fu lie, ainc ne fu si.

Contre lui en piés sali.

Quant or le voit Aucassins,

Andex ses bras li tendi,

Doucement le recoulli,

Les eus li baisse et le vis.

La nuit le laissent ensi,

Tresqu'au demain par matin

Que l'epousa Aucassins:

Dame de Biaucaire en fist.

Puis vesquirent il mains dis

Et menerent lor delis ${ }^{52}$.

\footnotetext{
SI R. M. Menocal, Op. cit., p. 510.

$52 \mathrm{~J}$. DufOuRnet, Op. cit., p. 162.
} 
No nos gustaría concluir el presente artículo sin dejar de destacar, una vez más, que la inversión en los roles de identidad de género o, más concretamente, la heroicidad y la masculinidad que Nicolette sufre es el elemento que realmente permite un desarrollo positivo en le relato. Es lógico que así sea porque la progresiva pasividad y feminización del protagonista masculino, de aquel que tradicionalmente debería haber sido héroe, conduciría únicamente a la falta de acción en el relato y, por supuesto, a la desdicha de los amantes. Tal vez hablar de feminización pueda sorprendernos e, incluso, resultarnos alarmante, pero con el episodio de Torlore, en el que nos encontramos a un rey recuperándose en la cama porque afirma haber dado a luz y teniendo en cuenta que dicho episodio es un reflejo irrisorio y absurdo, tal vez llevado al extremo, pero real al mismo tiempo, de lo que ocurre a Aucassin y Nicolette, pensar en la feminización del que debiera ser héroe salvador creemos que no resulta tan desacertado. Tal vez por este carácter tan tremendamente subversivo con lo masculino y lo femenino en un relato que se pretende como un himno a la mujer y en el que ésta adquiere un protagonismo y un rol inusitados en detrimento de los valores patriarcales y hegemónicos imperantes aún en la Francia del siglo XIII, el éxito de Aucassin et Nicolette sólo se refleja en la pervivencia de un único manuscrito y en una única obra, la que acabamos de mencionar, como representación de la chantefable. Desde luego, no es éste el único valor subversivo en $\mathrm{Au}$ cassin et Nicolette. Ya empezábamos definiendo nuestro relato como subversión y parodia de buena parte de los géneros medievales y, en especial, de la novela cortés. De ahí también, quizás, el silenciamiento del que la chantefable fue víctima a lo Jargo de todo el medievo, como la crítica ha intentado demostrar. 